\title{
Simultaneous measurements of heat of hydration and chemical shrinkage on hardening cement pastes
}

\author{
Pietro Lura · Frank Winnefeld • Stefanie Klemm
}

Received: 1 September 2009/Accepted: 22 October 2009/Published online: 3 December 2009

(C) Akadémiai Kiadó, Budapest, Hungary 2009

\begin{abstract}
Isothermal calorimetry and chemical shrinkage measurements are two independent techniques used to study the development of hydration in cementitious systems. In this study, calorimetry and chemical shrinkage measurements were combined and simultaneously performed on hydrating cement paste samples. Portland cement pastes with different water to cement ratios and a cement paste containing calcium sulfoaluminate clinker and anhydrite were studied. The combined calorimetry/chemical shrinkage test showed good reproducibility and revealed the different hydration behavior of sealed samples and open samples, i.e., samples exposed to external water during hydration. Large differences between sealed and open samples were observed in a Portland cement paste with low water to cement ratio and in the calcium sulfoaluminate paste; these effects are attributed to self-desiccation of the sealed pastes. Once the setup is fully automatized, it is expected that combined calorimetry/chemical shrinkage measurements can be routinely used for investigating cement hydration.
\end{abstract}

Keywords Cement hydration - Isothermal calorimetry · Chemical shrinkage · Ordinary Portland cement .

Calcium sulfoaluminate cement

$\begin{array}{ll}\text { Abbreviations } \\ \text { OPC } & \text { Ordinary Portland cement } \\ \text { CSA } & \text { Calcium sulfoaluminate clinker } \\ \text { Cs } & \text { Anhydrite } \\ \text { w/c } & \text { Water to cement ratio }\end{array}$

P. Lura $(\bowtie) \cdot$ F. Winnefeld $\cdot$ S. Klemm Empa, Swiss Federal Laboratories for Materials Testing and Research, Laboratory for Concrete and Construction Chemistry, Überlandstrasse 129, 8600 Dübendorf, Switzerland e-mail: pietro.lura@empa.ch

\section{Introduction}

The processes causing stiffening, setting, and hardening of cementitious pastes are of major importance for the practical applications of mortars and concretes. Many properties of cementitious materials, for instance early-age strength development, heat release, and crack resistance are influenced by their initial hydration rate. Isothermal calorimetry is one of the tools widely used to characterize the early hydration reactions of cementitious pastes, mostly as a "screening test". The sum of the dissolution and precipitation reactions occurring during cement hydration is an exothermal process that can be followed by calorimetry. Typical applications of the method are the optimization of the calcium sulfate set regulator, the evaluation of the impact of admixtures like retarders or superplasticizers on hydration kinetics and the assessment of the reactivity of mineral additions, like blastfurnace slags, metakaolin [1], or fly ash [2], in cementitious systems.

The kinetic information obtained from the heat flow signal is normally correlated with other data characterizing the evolution of chemical, physical, and microstructural properties of cement pastes [3]. These complementary data are generally measured using separate specimens and experimental setups. Thus, the question arises, if the experimental conditions and the sample preparation required by the various techniques are comparable.

As cement hydrates, the hydration products occupy less volume than the initial reacting materials, i.e., cement and water. Before setting, this volume change will result in a bulk contraction of the whole cement paste; after setting empty pores will be created [4]. Due to this volume change, a hydrating cement paste will absorb water from its immediate surroundings, when available. Chemical shrinkage can thus be measured by monitoring the amount 
of water that is absorbed by a cement paste during hydration. According to Parrot et al. [5], in the early hydration times, the amount of water sorbed is directly proportional to the amount of hydration that has occurred. Besides indicating the extent of hydration, chemical shrinkage measures the amount of voids formed within a cement paste and thereby may indicate the susceptibility of a cement paste to self-desiccation [6, 7]. The divergence between chemical and autogenous shrinkage, i.e., the free external shrinkage measured in sealed conditions at constant temperature, has also been used as a measure of setting [3, 4].

Recently, an ASTM standard for chemical shrinkage measurements has become available [8], which is based on the method developed by Geiker [9]. According to the ASTM standard, fresh cement paste is inserted into a glass vial, the vial is filled with water and the amount of chemical shrinkage is measured by reading the level change in a graduated pipette at regular intervals (Procedure A, volumetric method in [8]). Another method is based on the change in buoyancy of a specimen of hydrating cement paste immersed in a liquid $[6,9,10]$. This second method is easier to automatize but is more expensive since a dedicated high-precision balance is needed. An important requisite for chemical shrinkage tests is that the samples and the whole setup are kept in close-toisothermal conditions; this is often realized by immersing the samples in a thermostatized water bath [8]. When testing chemical shrinkage on cement pastes with low water to cement ratios (w/c), the capillary porosity may become disconnected and this may hinder the water absorption and invalidate the results. For this reason, either relatively high w/c pastes should be used [8] or extremely thin specimens, not more than a few millimeter thick [6,9].

Chemical shrinkage and isothermal calorimetry can be advantageously combined to study the early-age reactions in cementitious systems. Measurements of enthalpy and volume change on the same cement pastes can help determining which reactions are taking place at each moment during the hydration process $[11,12]$. The present study aims at integrating the two techniques even further, by measuring the two properties on the same sample. The combined measurement of heat of hydration and chemical shrinkage in the same cell of a commercially available calorimeter will allow cheaper and faster assessment of different cement types, supplementary cementitious materials, mixture compositions, and effect of admixtures.

\section{Materials and methods}

Two cement pastes with ordinary Portland cement (OPC) and a cement paste containing calcium sulfoaluminate clinker (CSA), based on ye'elimite $4 \mathrm{CaO} \cdot 3 \mathrm{Al}_{2} \mathrm{O}_{3} \cdot \mathrm{SO}_{3}$, and anhydrite (Cs) were used in this study. The latter system has attracted new interest during the climate debate, as it is a promising candidate for producing cementitious binders with low $\mathrm{CO}_{2}$ impact [13]. The OPC was a CEM I 42.5 Portland cement with density $3,130 \mathrm{~kg} / \mathrm{m}^{3}$ and Blaine fineness $2,810 \mathrm{~cm}^{2} / \mathrm{g}$. The CSA clinker had density $2,770 \mathrm{~kg} / \mathrm{m}^{3}$ and Blaine fineness $4,770 \mathrm{~cm}^{2} / \mathrm{g}$. An anhydrite with density $2,920 \mathrm{~kg} / \mathrm{m}^{3}$ and Blaine fineness $3,820 \mathrm{~cm}^{2} / \mathrm{g}$ was used. The analyses of the three products are given in Table 1. Notice that in Table 1, according to cement chemistry notation: $\mathrm{A}=\mathrm{Al}_{2} \mathrm{O}_{3}, \quad \mathrm{C}=\mathrm{CaO}$, $\mathrm{F}=\mathrm{Fe}_{2} \mathrm{O}_{3}, \mathrm{~S}=\mathrm{SiO}_{2}, \mathrm{~s}=\mathrm{SO}_{3}, \mathrm{~T}=\mathrm{TiO}_{2}$.

The two OPC pastes had w/c 0.5 and 0.3 ; to the paste with w/c 0.3 , a commercial polycarboxylate-based superplasticizer (solid content $30 \%$ by mass) was added at a dosage of $0.4 \%$ by mass of cement referred to the solid content of the superplasticizer. The CSA cement paste had a CSA/anhydrite ratio of $3: 1$ by mass and a water/binder ratio of 0.7 . The cement pastes were mixed with deionized water in a vacuum mixer (Twister evolution) for $2 \mathrm{~min}$ at $450 \mathrm{rev} / \mathrm{min}$.

Three different experimental setups were used, (i) a sole calorimetric experiment, (ii) a sole chemical shrinkage experiment, and (iii) a combined calorimetric/chemical shrinkage experiment.

A commercial conduction calorimeter with eight measuring cells, TAM Air by Thermometric, was used for the experiments. About $6 \mathrm{~g}$ of freshly mixed cement paste were weighed into a glass vial of internal diameter $22.5 \mathrm{~mm}$, which was then capped and placed into the calorimeter. Due to the external mixing, the initial heat peak

Table 1 Chemical analysis and phase composition of the materials used

\begin{tabular}{|c|c|c|c|c|c|c|c|}
\hline & OPC & CSA & Cs & OPC & & CSA & \\
\hline \multicolumn{4}{|c|}{ Chemical analysis $/ g / 100 g^{\mathrm{a}}$} & \multicolumn{4}{|c|}{ Normative composition $/ \mathrm{g} / 100 \mathrm{~g}$} \\
\hline $\mathrm{CaO}$ & 61.9 & 36.2 & 40.3 & $\mathrm{C}_{3} \mathrm{~S}^{\mathrm{d}}$ & 56.1 & $\mathrm{C}_{4} \mathrm{~A}_{3} \mathrm{~s}^{\mathrm{d}}$ & 68 \\
\hline $\mathrm{SiO}_{2}$ & 19.6 & 4.1 & 0.8 & $\beta-\mathrm{C}_{2} \mathrm{~S}^{\mathrm{d}}$ & 15.5 & $\mathrm{C}_{2} \mathrm{AS}^{\mathrm{d}}$ & 14 \\
\hline $\mathrm{Al}_{2} \mathrm{O}_{3}$ & 5.1 & 44.8 & 0.3 & $\mathrm{C}_{3} \mathrm{~A}^{\mathrm{d}}$ & 4.8 & $\mathrm{C}_{3} \mathrm{~A}^{\mathrm{d}}$ & \\
\hline $\mathrm{Fe}_{2} \mathrm{O}_{3}$ & 2.9 & 1.3 & 0.2 & $\mathrm{C}_{4} \mathrm{AF}^{\mathrm{d}}$ & 11.5 & $\mathrm{CA}^{\mathrm{d}}$ & 7. \\
\hline $\mathrm{MgO}$ & 2.3 & 1.1 & 0.1 & $\mathrm{MgO}^{\mathrm{d}}$ & 1.0 & $\mathrm{CA}_{2}^{\mathrm{d}}$ & 1. \\
\hline $\mathrm{K}_{2} \mathrm{O}$ & 1.01 & 0.25 & 0.04 & $\mathrm{~K}_{2} \mathrm{SO}_{4}^{\mathrm{e}}$ & 1.6 & $\mathrm{CT}^{\mathrm{d}}$ & 3. \\
\hline $\mathrm{Na}_{2} \mathrm{O}$ & 0.26 & 0.07 & 0.03 & $\mathrm{Na}_{2} \mathrm{SO}_{4}^{\mathrm{e}}$ & 0.26 & $\mathrm{MgO}^{\mathrm{d}}$ & 1 . \\
\hline $\mathrm{SO}_{3}$ & 3.0 & 8.9 & 57.2 & $\mathrm{~K}_{2} \mathrm{O}^{\mathrm{e}}$ & 0.13 & $\mathrm{CaO}_{\text {free }}^{\mathrm{f}}$ & $<0$. \\
\hline $\mathrm{TiO}_{2}$ & 0.28 & 2.19 & 0.01 & $\mathrm{Na}_{2} \mathrm{O}^{\mathrm{e}}$ & 0.15 & & \\
\hline $\mathrm{P}_{2} \mathrm{O}_{5}$ & 0.20 & 0.08 & 0.03 & $\mathrm{CaO}_{\text {free }}^{\mathrm{f}}$ & 0.27 & Cs & \\
\hline $\mathrm{SrO}$ & 0.15 & 0.12 & n. d. & $\mathrm{CaCO}_{3}^{\mathrm{d}}$ & 4.8 & $\mathrm{Cs}^{\mathrm{d}}$ & $>97$ \\
\hline LOI & $2.68^{\mathrm{b}}$ & $0.72^{\mathrm{b}}$ & $0.56^{\mathrm{c}}$ & $\mathrm{CaSO}_{4} \cdot 2 \mathrm{H}_{2} \mathrm{O}^{\mathrm{d}}$ & 4.0 & & \\
\hline
\end{tabular}

${ }^{\mathrm{a}}$ XRF data uncorrected for loss on ignition, ${ }^{\mathrm{b}} 950{ }^{\circ} \mathrm{C},{ }^{\mathrm{c}} 900{ }^{\circ} \mathrm{C}$, ${ }^{\mathrm{d}}$ from Rietveld analysis, ${ }^{\mathrm{e}}$ from extended Bogue calculation, ${ }^{\mathrm{f}}$ from chemical analysis (extraction method) 
right after the addition of water to cement could not be measured. The heat flow was then recorded for about $80 \mathrm{~h}$. Measuring temperature was $20^{\circ} \mathrm{C}$; during the experiment, the measuring cells within the calorimeter are kept at constant temperature $\pm 0.02{ }^{\circ} \mathrm{C}$.

Chemical shrinkage was measured according to Procedure A described in ASTM Standard C 1608-07 [8]. About $6 \mathrm{~g}$ of freshly mixed cement paste were inserted in the same glass vials used in the calorimetric experiment. This resulted in samples with height about $6-7 \mathrm{~mm}$ and surface area about $400 \mathrm{~mm}^{2}$. Unlike the calorimetric experiment described above, the surface of the paste was covered with a thin layer (about $0.5 \mathrm{~g}$ ) of deaired, demineralized water. The vial was subsequently filled with paraffin oil and closed with a rubber stopper, through which a graduated pipette with a total volume of $1 \mathrm{~mL}$ and an accuracy of $0.01 \mathrm{~mL}$ was inserted (see Fig. 1, left); the vials were immersed in a controlled water bath at $20{ }^{\circ} \mathrm{C}$. Measurements were performed by reading the oil level of the graduated pipettes at regular intervals during 3 days on three replicate specimens. Figure 1, left, shows a view of a glass vial with graduated pipettes [8].

In the third setup, chemical shrinkage measurements were coupled with calorimetry by performing the experiments within the calorimeter cells. For each mixture, chemical shrinkage and heat of hydration were measured in parallel on three specimens, while on a further reference specimen only heat flow was measured (see previous paragraph). After weighing about $6 \mathrm{~g}$ of cement paste into a calorimetry glass vial, the surface of the paste was covered with a thin layer (about $0.5 \mathrm{~g}$ ) of deaired, demineralized water. The vials were then completely filled with paraffin oil and closed with a rubber stopper, provided with a graduated capillary with $0.01 \mathrm{~mL}$ resolution. Figure 1,

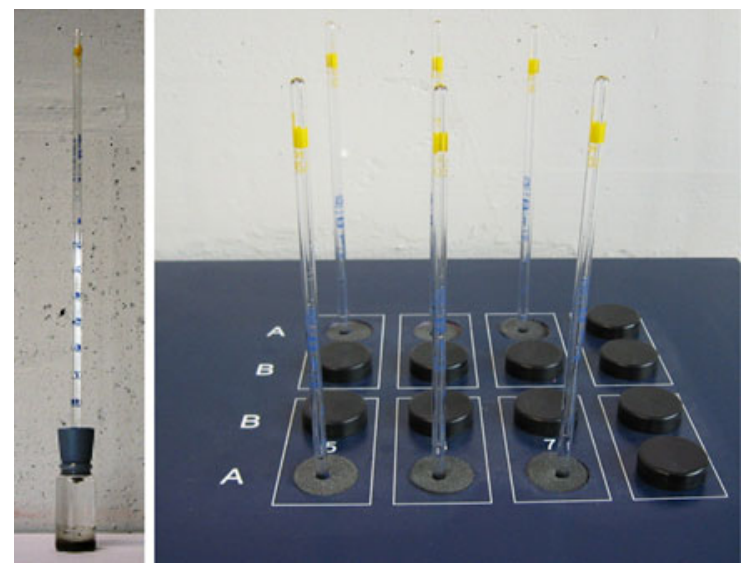

Fig. 1 Glass vial with graduated pipette for measurements of chemical shrinkage (left) and external view of the calorimeter showing the oil-filled graduated pipettes protruding from the glass vials in the combined calorimetry/chemical shrinkage setup (right) right, shows the modified calorimeter with insertion of the capillaries. In order to obtain a good thermal insulation of the measuring cells, $20 \mathrm{~mm}$ thick rubber foam plugs were employed. For the vials with the chemical shrinkage setup, a separate calibration of the calorimeter cells was carried out to take into account the impact of the different vessels. In contrast to the sole calorimetric experiment, where no extra water is added, in this combined setup a layer of extra water is present on top of the paste.

\section{Results}

Figures 2 and 3 show both heat flow and cumulative heat of hydration of the three cement pastes. The cumulative heat of hydration was obtained by integration of the heat flow. As explained in the previous session, chemical shrinkage and heat flow were measured simultaneously on three specimens, while heat flow alone was measured on one specimen.

In the sole calorimetric setup, the plain OPC paste with w/c 0.5 (Fig. 2) shows, after the initial heat event, a dormant period associated with a relatively low heat flow until about $2 \mathrm{~h}$ of hydration time. This is followed by an increase in heat flow over several hours during the
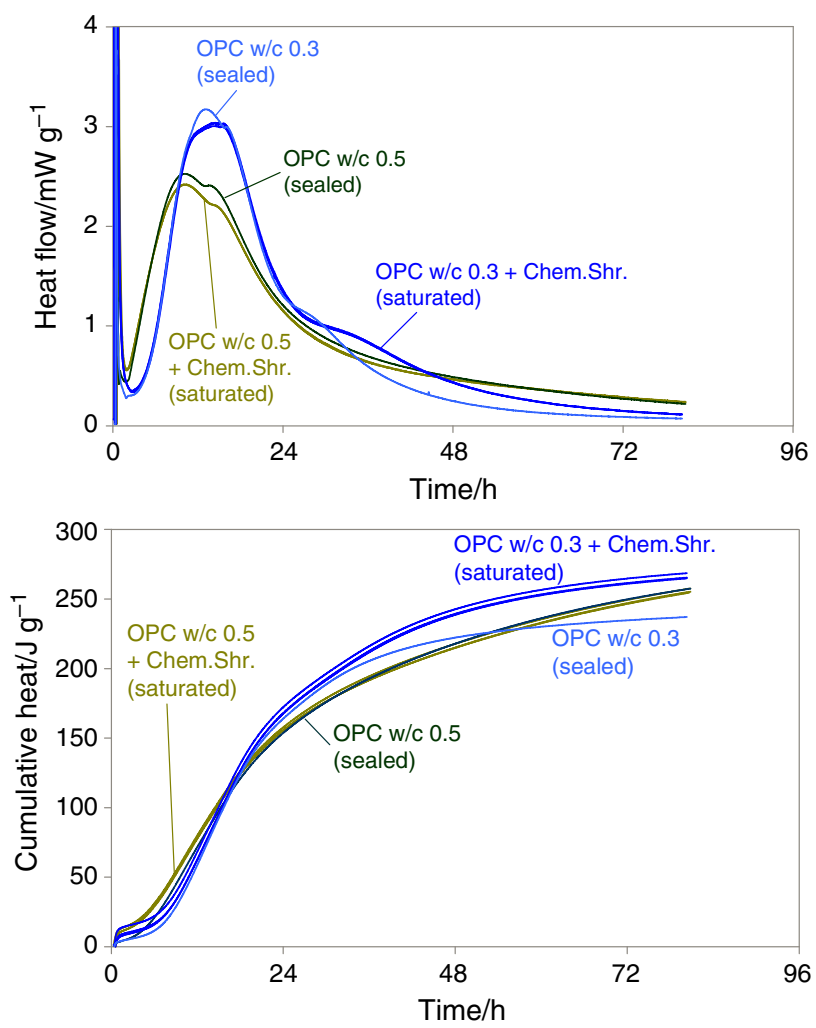

Fig. 2 Heat flow (above) and cumulative heat of hydration (below) of OPC pastes with w/c 0.5 and 0.3 

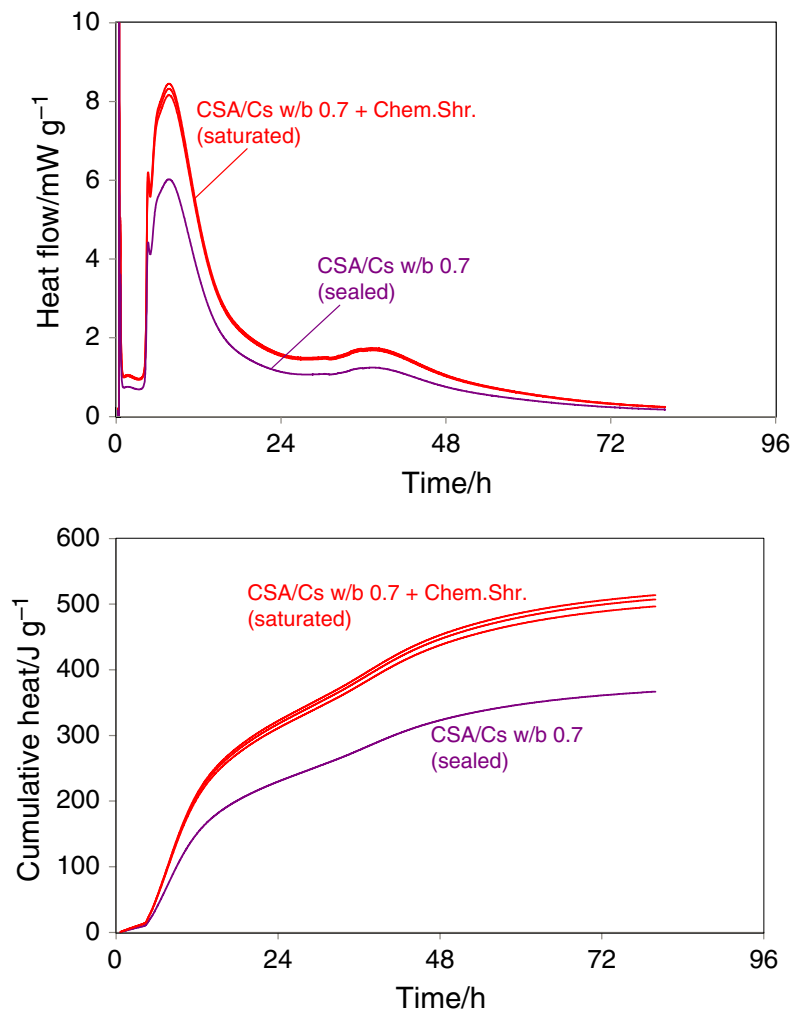

Fig. 3 Heat flow (above) and cumulative heat of hydration (below) of CSA pastes with $\mathrm{w} / \mathrm{b} 0.7$

acceleration period toward a maximum after about $10 \mathrm{~h}$, mainly due to the effects of tricalcium silicate (alite) reacting to calcium silicate hydrates and calcium hydroxide. An additional peak is observed after about $15 \mathrm{~h}$. It represents the time when the calcium sulfate set regulator is consumed and the remaining tricalciumaluminate phase $\left(\mathrm{C}_{3} \mathrm{~A}\right)$ reacts no longer to ettringite (calcium aluminate trisulfate hydrate) but to other phases like monosulfate or monocarbonate; this was confirmed by X-ray diffraction and thermogravimetric analysis for the samples investigated in this study [14]. After this peak, there is a steady decrease in the heat flow (deceleration period), which soon reaches a constant, low value (final period). In comparison, the OPC paste with w/c ratio of 0.3 is retarded due to the added superplasticizer $[15,16]$ exhibiting a longer dormant period (about $3 \mathrm{~h}$ ) and a later maximum of the main hydration peak (at about $12 \mathrm{~h}$ ). The peak representing the calcium sulfate depletion cannot clearly be recognized, because it probably superimposes the main hydration peak.

When comparing the combined measurements with the sole calorimetric experiment, the OPC paste with w/c 0.5 (Fig. 2) exhibits a similar rate of heat evolution in all specimens, however the sealed specimen shows a slightly lower heat flow in the dormant period (first $2 \mathrm{~h}$ ) and slightly higher peaks at 10 and $15 \mathrm{~h}$; the cumulative heat of hydration at 3 days is similar for all specimens. The OPC paste with w/c 0.3 (Fig. 2) also shows a similar heat flow in all specimens in the first hours; however the sealed specimen yields a higher main hydration peak compared to the specimens with water on top. Moreover, the sealed specimen shows an additional peak indicating sulfate depletion, which is under these conditions not superimposed on the main hydration peak. Thus, in the first hours of hydration, the experimental conditions (sealed vs. additional water on top) mainly influence the reactions of the tricalcium aluminate phase and their kinetics in this OPC system. Probably the extra water makes more calcium sulfate available to react with $\mathrm{C}_{3} \mathrm{~A}$ to ettringite and thus delays the additional peak. Starting at about $24 \mathrm{~h}$, heat flow in the sealed specimen decreases substantially, while it decreases much less in the samples with water on top.

Compared to the OPC systems, the CSA mixture (Fig. 3) exhibits about twice the cumulative heat of hydration. Unlike OPC, the hydration of such a mixture is mainly based on the reaction of the ye'elimite phase (calcium aluminum sulfate, $\mathrm{C}_{4} \mathrm{~A}_{3} \mathrm{~s}$ ) with calcium sulfate to ettringite and, when the calcium sulfate is depleted, to monosulfate [17, 18]. For complete hydration, a water/ binder ratio of about $0.50-0.70$ is needed for a typical CSA cement; for comparison, an OPC needs about 0.23 [19]. Notice that these figures include only the chemically bound water in the hydration products, while a further amount of water becomes physically bound as adsorbed water on the surface of the hydrates; this water is not available for hydration of cement [19]. The presence of absorbed water will thus increase the w/c required for complete hydration of Portland cement to typical values of $0.40-0.42$.

The sealed sample in the CSA mixture shows a dormant period after the initial heat event, until the heat flow starts to increase again after about $4 \mathrm{~h}$. The maximum heat flow is reached after $7 \mathrm{~h}$. An additional maximum at a lower heat flow is reached after a hydration time of $36 \mathrm{~h}$, which can be associated to the depletion of the added anhydrite $[14,17,18]$. In contrast to the OPC system, the CSA mixture exhibits a much higher heat evolution for the saturated specimens compared with the sealed one right from the end of the induction period. It is remarkable that the shape and the position in time of the hydration peaks do not seem to be influenced by the presence of extra water, but the amount of evolved heat is substantially increased in the saturated specimens.

Figure 4 shows chemical shrinkage measurements on the three cement pastes performed either as a stand-alone test (empty symbols in Fig. 4) or within the calorimeter cell (full symbols in Fig. 4). The chemical shrinkage is plotted as milliliter per gram of binder in the mixture. The CSA paste shows an early development of chemical shrinkage in the first days of hydration, and a magnitude at $72 \mathrm{~h}$ that is about four times larger than for the OPC pastes. 


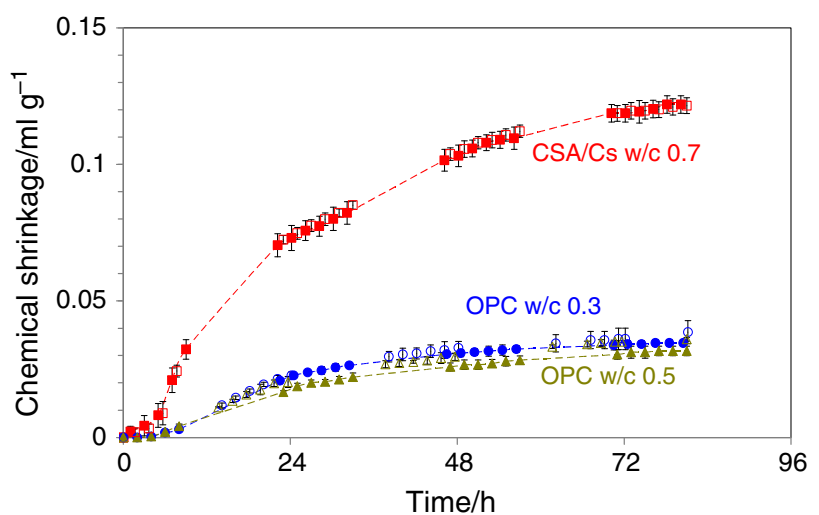

Fig. 4 Chemical shrinkage measured in the calorimeter cells (full symbols) and measured separately (empty symbols) on OPC and CSA pastes. Standard deviation bars are indicated for all measurements

This is in good agreement with theoretical calculations of chemical shrinkage of CSA cements derived from a thermodynamic hydration model [17]. Very similar results are obtained with the two setups for all three cement pastes, with curves that can almost be superimposed.

In Fig. 5, chemical shrinkage as a function of heat of hydration for CSA and OPC pastes is shown. The chemical shrinkage curves measured within the calorimeter are plotted against the heat of hydration measured on the same samples (full symbols in Fig. 5). Both for chemical shrinkage and for heat of hydration, the average of three samples is plotted. It is noticed that the relationship between heat of hydration and chemical shrinkage appears to be roughly linear for the three cement pastes. Moreover, except for an initial shift in the first few hours, the slope appears to be the same for the two OPC pastes, indicating that the slope is independent of $w / c$. The slope of the chemical shrinkage versus heat of hydration line for the CSA paste is about 1.8 times the slope for the OPC pastes; on average, the hydration reactions in the CSA system happen with about twice as much chemical shrinkage per amount of heat liberated as in the OPC pastes. In addition, in Fig. 5 the open symbols represent the results of heat of hydration of specimens with no water on top, plotted against the chemical shrinkage measured on the companion specimens. As these properties have been measured on samples in different conditions, namely on sealed samples (heat of hydration) and on samples with free access to water (chemical shrinkage), the slope of the curves is different. For the CSA mixture (Fig. 5, left), it becomes clear that the heat of hydration in the sealed sample becomes lower than for the saturated sample starting at low values of chemical shrinkage. With the progress of hydration and chemical shrinkage, this difference between sealed and saturated samples becomes even greater. In the case of the OPC mixtures (Fig. 5, right), no clear difference between sealed and saturated samples is apparent for the w/c 0.5 cement paste, while for the w/c 0.3 paste the curves
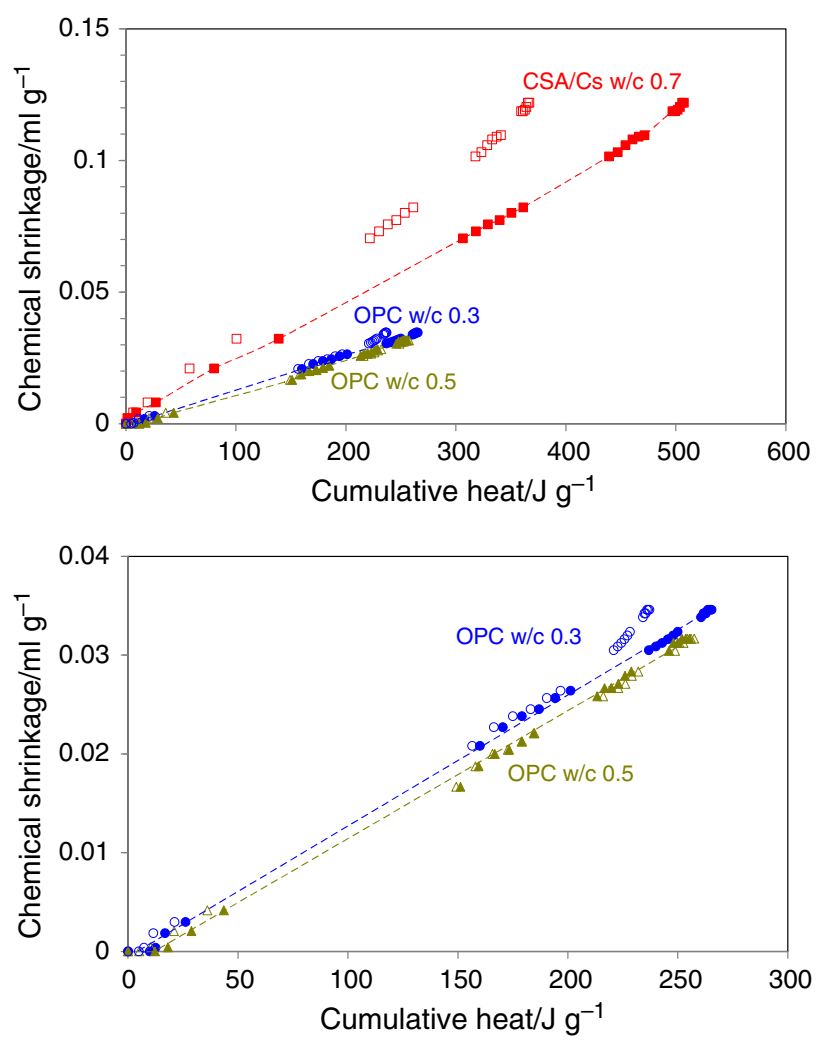

Fig. 5 Chemical shrinkage as a function of cumulative heat of hydration for CSA and OPC pastes (above) and only for two OPC pastes with different w/c ratio (below). The full symbols show the results of open samples where chemical shrinkage and heat flow were measured simultaneously, while the open symbols represent the heat of hydration of specimens with no water on top

start to diverge at heat of hydration larger than about $200 \mathrm{~J} / \mathrm{g}$. This corresponds to the deviation occurring around $30 \mathrm{~h}$ in Fig. 2 (below).

\section{Discussion}

Both the heat flow and the chemical shrinkage measurements in the calorimeter cell show a good reproducibility. The hydration heat of three identical samples shows minimal scatter (Figs. 2, 3); the differences in hydration kinetics and in total evolved heat observed between sealed samples and samples with access to water will be discussed in the following paragraph. No substantial differences between chemical shrinkage measurements ex-situ and in the calorimeter cell were observed (Fig. 4). It appears that measurements of chemical shrinkage inside the calorimeter are at least as efficient as the measurements following the procedure according to ASTM C-1608-07 [8].

It has been noticed that the heat evolution of the samples where chemical shrinkage was measured was generally higher than that of the control samples, especially for the 
CSA mixture and to a lesser extent for the OPC mixtures with w/c 0.3. An explanation of this fact is that the samples where chemical shrinkage was measured were exposed to external water for the duration of the experiment, i.e., they can be considered as an open system with water-saturated porosity, unlike the control samples that hydrated in sealed conditions, without access to external water. The latter consequently self-desiccated, the hydration reaction slowed down after the consumption of water and the final degree of hydration reached was lower. A confirmation of this can be seen in OPC paste with w/c 0.3: hydration proceeded similarly in all samples in the first $30 \mathrm{~h}$, after which the heat liberation of the control samples (with no water on top) was clearly lower (Fig. 2). On the contrary, no difference between sealed and open samples was observed for the OPC paste with w/c 0.5 (Fig. 2). This may be attributed to the fact that the amount of water in this paste is sufficient to achieve full hydration of the cement, as the theoretical water demand for complete hydration of Portland cement, including chemically bound water and water absorbed by the hydrates, is about 0.40-0.42 [19]. Consequently, in this case the presence of additional water should not influence the amount of heat liberated at later ages.

The correctness of the assumption of self-desiccation and the effect of external water can be tested in the case of OPC by comparing the heat liberation at the end of the experiment in the closed (sealed) and open (saturated) systems with w/c 0.3 . The ratio of the heat liberation in the closed and open systems after several days (for e.g., at the end of the experiment, at about $80 \mathrm{~h}$ ) can be assumed equal to the ratio of the degree of hydration at the same time:

$\frac{Q_{\mathrm{C}}}{Q_{\mathrm{O}}}=\frac{\alpha_{\mathrm{C}}}{\alpha_{\mathrm{O}}}$

where $Q_{\mathrm{C}}, \alpha_{\mathrm{C}}, Q_{\mathrm{O}}$, and $\alpha_{\mathrm{O}}$ are the heat liberation and the degree of hydration in the closed and in the open system.

The ratio between the degree of hydration in a closed and in an open Portland cement system can also be estimated with Powers' model (see e.g., [20]). For a 0.3 w/c OPC paste, a closed system reaches a final degree of hydration of about 0.72 , while an open system reaches a degree of hydration of about 0.86 . This gives a ratio of $\frac{\alpha_{C}}{\alpha_{0}}$ equal to 0.83 . On the other hand, the measured ratio $\frac{Q_{\mathrm{C}}}{Q_{\mathrm{O}}}$ after $80 \mathrm{~h}$, as derived from Fig. 2, below, is 0.89. These two values compare reasonably well, considered the approximations involved in Powers' model and the fact that the calculated ratio between the degrees of hydration is a final value at infinite time, while at $80 \mathrm{~h}$ the tested cement pastes were still liberating heat, as evident from Fig. 2, left.

The CSA cement paste exhibits an even larger effect of self-desiccation on heat of hydration; in fact, the sealed sample at $80 \mathrm{~h}$ evolved only about 0.72 times the heat of the sample with water on top. By applying thermodynamic modelling [17], it is calculated that the CSA/anhydrite mixture needs a water/binder ratio of 0.58 for complete hydration. Ettringite ( $82 \mathrm{~g} / 100 \mathrm{~g}$ dry binder), monosulfate (32 g/100 g dry binder) and amorphous aluminum hydroxide $(28 \mathrm{~g} / 100 \mathrm{~g}$ dry binder) are predicted to occur as hydration products. This is confirmed qualitatively by XRD and TGA analyses of hydrated pastes at several sample ages up to 28 days [14]. It is noticed that this calculation does not take into account the water adsorbed on the hydrates. In fact, no model like Powers' is currently available for CSA cements as they have been by far not so extensively studied as OPC. As a consequence, the amount of water adsorbed on the surface of the hydrates, especially of ettringite and amorphous aluminum hydroxide, is unknown. A fast selfdesiccation might also be connected to the very rapid development of a dense microstructure in CSA cements [17], which causes also the development of higher early strengths compared to Portland cements [18]. The dense structure, with many small pores and hydrates of high surface areas, probably slows down the hydration kinetics of the CSA systems due to decreased mobility of the free water. As selfdesiccating pastes have a high propensity for autogenous shrinkage [21], the results presented in this article indicate the need for investigating microstructure formation, selfdesiccation, and early-age shrinkage in CSA cement pastes.

It should be remembered that samples on which hydration reactions are studied with different techniques should ideally be in the same conditions, i.e., should react at the same temperature and in the same moisture conditions. By performing the chemical shrinkage in the calorimeter cell, these conditions are fulfilled and both properties are measured on open systems, with free access to external water. It must be pointed out that this is not generally the case for isothermal calorimetry, where the tests are normally performed on sealed samples. For OPC cement pastes and when the w/c is high, results of closed and open systems should not differ considerably; however, the results of this article show that at low w/c and for different binder types (i.e., CSA systems), heat flow of closed and open systems may vary considerably. Comparison of the heat evolution measured on closed or open samples could help shedding light on the effect of self-desiccation and low relative humidity on the hydration of cement.

A further remark concerns the possibility of automatizing the chemical shrinkage readings, which is of utmost importance for a possible industrial application of the combined calorimetry/chemical shrinkage technique. The automatization is not only desirable to reduce manpower and related costs, but also to allow monitoring of the samples at night and possibly to improve the accuracy of the readings. While chemical shrinkage measurements based on the buoyancy principle can be conveniently automatized with a digital balance $[6,9,10]$, this type of 
setup cannot be easily combined with the measurements within a calorimeter cell. Therefore, a method to automatize the readings of the oil level in the capillaries has to be preferred. Buil [22] proposed a method involving the use of a photoelectric cell. Fontana [23] described a method in which the water level in a capillary is followed with an electrical capacity measurement in a coaxial tube. Another method where liquid levels in multiple capillary tubes are recorded automatically with a digital camera was recently developed [24]. Zhang et al. [25] measured chemical shrinkage by monitoring the change in hydraulic head with a pressure sensor. Any of these methods could be applied also to the calorimetry/chemical shrinkage setup described in this article, thereby realizing a fully automatized setup.

\section{Conclusions}

This study showed that it is possible to combine calorimetry and chemical shrinkage measurements on hydrating cement pastes simply by performing the chemical shrinkage test within the calorimeter cells. The reproducibility of the combined heat of hydration and chemical shrinkage measurements is similar to the one of the standalone tests. The combined setup guarantees that chemical shrinkage and heat of hydration are measured on cement pastes that hydrate exactly at the same temperature and in the same moisture conditions, i.e., saturated with water.

In particular, this study showed the application of combined calorimetry/chemical shrinkage for revealing the hydration behavior of OPC systems with different w/c and CSA systems.

Several strategies are available in the literature to automatize the chemical shrinkage measurements; it is expected that fully automatized combined calorimetry/ chemical shrinkage setups can be routinely used in research and industrial applications for studying hydration and early-age properties of cementitious mixtures.

\begin{abstract}
Acknowledgements This project was funded by the Nanocem consortium under the project "Studying early age reactions of cementitious pastes by an in situ combination of isothermal calorimetry with other methods". Stimulating discussion with Lars Wadsö, Mette Geiker, Laure Pelletier and Ellis Gartner is gratefully acknowledged.
\end{abstract}

\section{References}

1. Rahhal V, Talero R. Calorimetry of Portland cement with metakaolins, quartz and gypsum additions. J Therm Anal Calorim. 2008;91(3):825-34.

2. Baert G, Hoste S, De Schutter G, De Belie N. Reactivity of fly ash in cement paste studied by means of thermogravimetry and isothermal calorimetry. J Therm Anal Calorim. 2008;94(2): 485-92.

3. Sant G, Dehadrai M, Bentz D, Lura P, Ferraris CF, Bullard JW, et al. Detecting the fluid-solid transition in cement paste. Comparing experimental and numerical techniques. Concr Int. 2009;31(6):54-8.

4. Lura P, Couch J, Jensen OM, Weiss J. Early age acoustic emission measurements in hydrating cement paste: evidence for cavitation during solidification due to self-desiccation. Cem Concr Res. 2009;39(10):861-7.

5. Parrott LJ, Geiker M, Gutteridge WA, Killoh D. Monitoring Portland cement hydration: comparison of methods. Cem Concr Res. 1990;20:919-26.

6. Sant G, Lura P, Weiss J. Measurement of volume change in cementitious materials at early ages. Review of testing protocols and interpretation of results. Transp Res Rec. 2006;1979:21-9.

7. Lura $P$, Jensen OM. Measuring techniques for autogenous strain of cement paste. Mater Struct. 2007;40:431-40.

8. ASTM C-1608-07. Standard Test Method for Chemical Shrinkage of Hydraulic Cement Paste. ASTM International, 2007.

9. Geiker M. Studies of Portland cement hydration: measurements of chemical shrinkage and a systematic evaluation of hydration curves by means of the dispersion model. Ph.D. Thesis. Technical University of Denmark, Copenhagen, Denmark. 1983.

10. Knudsen T, Geiker M. Obtaining hydration data by measurement of chemical shrinkage with an archimeter. Cem Concr Res. 1985;15(2):381-2.

11. Wesselsky A, Jensen OM. Quantification of early age hydration of Portland cement and pure cement phases. $\mathrm{PhD}$ project description. 2006. http://www.irs.byg.dtu.dk/Current\%20research/AW.aspx.

12. Geiker MR, Kjeldsen AM, Gallucci E, Bager DH. Preliminary investigation of the effect of air-pollution-control residue from waste incineration on the properties of cement paste and mortar. In: Proceedings of advances in cement and concrete X, sustainability. Davos, Switzerland; July 2006, p. 201-205.

13. Gartner E. Industrially interesting approaches to "low-CO2" cements. Cem Concr Res. 2004;34(9):1489-98.

14. Klemm S. Charakterisierung der Zementhydratation mit einer in situ Kombination von Wärmeflusskalorimetrie und chemischem Schwinden (in German). Internship Thesis. Empa, Switzerland and Technical University of Freiberg, Ger-many; 2009. 100 p.

15. Winnefeld F, Becker S, Pakusch J, Götz T. Effects of the molecular architecture of comb-shaped superplasticizers on their performance in cementitious systems. Cem Concr Comp. 2007; 29(4):251-62.

16. Zingg A, Winnefeld F, Holzer L, Pakusch J, Becker S, Figi R, et al. Interaction of polycarboxylate-based superplasticizers with cements containing different C3A amounts. Cem Concr Comp. 2009;31(3):153-62.

17. Winnefeld F, Lothenbach B. Hydration of calcium sulfoaluminate cements-Experimental findings and thermodynamic modelling. Cem Concr Res. 2010. doi:10.1016/j.cemconres.2009.08.014.

18. Winnefeld F, Barlag S. Calorimetric and thermogravimetric study on the influence of calcium sulfate on the hydration of ye'elimite. J Therm Anal Calorim. 2010. doi:10.1007/s10973-009-0582-6.

19. Powers TC, Brownyard TL. Studies of the physical properties of hardened Portland cement paste (9 parts). J ACI 43 (Oct. 1946 to April 1947). Bulletin 22. Chicago: Research Laboratories of the Portland Cement Association; 1947.

20. Lura P, Jensen OM, Igarashi S-I. Experimental observation of internal water curing of concrete. Mat Struct. 2007;40:211-20.

21. Lura $P$, van Breugel $\mathrm{K}$, Jensen OM. Autogenous shrinkage in high-performance cement pastes: an evaluation of basic mechanisms. Cem Concr Res. 2003;33(2):223-32. 
22. Buil M. Studies of the shrinkage of hardening cement paste (in French). D.Eng. thesis. Rapport de recherche LPC No. 92. Laboratoire Central des Ponts et Chaussées, Paris; 1979.

23. Fontana P. Einfluss der Mischungszusammensetzung auf die frühen autogenen Verformungen der Bindemittelmatrix von Hochleistungsbetonen (in German). Doctoral thesis. Technischen Universität Carolo-Wilhelmina zu Braunschweig, Germany. 2007. $150 \mathrm{p}$.
24. Costoya Fernández MM. Effect of particle size on the hydration kinetics and microstructural development of tricalcim silicate. Doctoral thesis. École Polytechnique Fédérale de Lausanne, Switzerland. 2008. 229 p.

25. Zhang J, Peethamparan S, Weissinger EA, Vocaturo J, Scherer GW. Early hydration and setting of oil well cement. Cem Concr Res. 2009 (submitted). 